\section{Abortion: the Crisis in Morals and Medicine}

Cameron and Pamela F Sims, 159 pages, Leicester, £2.25, Inter-Varsity Press, 1986.

Until recently the most vociferous opposition to the practice of therapeutic abortion was Roman Catholic in origin. In the contemporary debate, however, an even stronger anti-abortion stance is being taken by sections of evangelical protestantism. This short book is a statement of such a position, the authors being the warden of a conservative evangelical study centre and a consultant in obstetrics and gynaecology. Abortion is always to be condemned even on the grounds of rape, incest (the baby can always be adopted) and the near certainty of severe abnormality in the new-born baby. The possibility of abortion in the case of risk to the mother's life is conceded with reluctance though 'she must herself participate in that decision, and some women, aware of what the choice will mean, have opted instead to refuse treatment in order to save the life of the child' (page 99).

Attitudes to abortion in the theological tradition are surveyed, the 'text' of the argument being: 'As you did it unto the least of these my brethren you did it to me', and much is made of the belief that Jesus Christ was fully human from the point of conception. The legal position in the United Kingdom and elsewhere is examined together with what is considered to be the relevant medical data.

A whole chapter is devoted to a critique of the arguments in favour of abortion, in particular to the classic work by R F R Gardner (1) in which compassion for the mother was recognised as at least one factor in deciding to proceed with the termination of a pregnancy. 'We do not (at least we should not!) come to conclusions about what is right on the basis of being compassionate unless it is already clear to us that this is right in itself (page 93). Herein lies the weakness of the argument, for where there is ethical ambiguity then surely compassion has some part to play. There are those who would hold to a fully incarnational theology but do not see this as a starting point for discussion, or at least as the only factor to be considered. The argument is essentially one-sided. For those involved pastorally, while acknowledging the seriousness of the decision to terminate a pregnancy, there must be a concern for the total wellbeing of the mother. A pastoral ethic cannot emerge from a combination of theological assertion and relentless logic.

Many who are unhappy with the approach outlined in this book are equally unhappy with the number of abortions which take place. The sad thing about this position is that the middle ground is abandoned and debate concerning the criteria upon which abortions may legitimately proceed becomes that much more difficult.

A final chapter is devoted to an examination of embryo research. Not unexpectedly the authors are against it. Again the argument is one-sided and frequently of the 'thin end of the wedge' variety. Is there no compassion for the childless couple or any desire to find ways of preventing the development of abnormalities in the fetus?

\section{Reference}

(1) Gardner RFR. Abortion; the personal dilemma. Exeter: The Paternoster Press, 1972.

DAVID LYALL Chaplaincy Centre, Western General Hospital, Edinburgh

\section{Handbook for Hospital Ethics Committees}

Judith Wilson Ross, Sister Corrine Bayley, Vicki Michel and Deborah Pugh, 176 pages, Chicago, \$28.75; AHA Members $\$ 23.00$, American Hospital Publishing, Inc, 1986

This book is written by members of the Center for Bioethics, St Joseph Health System at Orange, California and is, not surprisingly, entirely American in its orientation. It is essentially a practical book, advising US ethical committees on their structure, membership procedures and functions as well as pointing out some problems and pitfalls. The legal (US) issues are considered with an appendix mentioning several case studies.

The book is well presented and readable and apparently comprehensive and it would be surprising if it was not well received in the US as being useful for any bioethical committee chairperson.

However, US committees on ethics seem to have a completely different function from those in the UK. In the

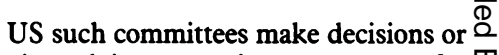
give advice on patient treatment, for $\underset{+}{m}$ example, who should or should not be given a DNR (do-not-resuscitate)? order. There is barely a mention on the ethics of medical-research procedures.

For this reason the book will be of limited value in the UK and elsewhere 흠 where committees are almost entirely $\frac{\bar{G}}{2}$ concerned with the ethics of research $\mathbb{D}$ procedures on the healthy and the sick $\frac{2}{2}$ and not concerned with the ethics of $\infty$ therapy.

IAN MACDONALD Professor of Applied Physiology, Head, Department of Physiology, $\overline{\overline{3}}$ United Medical and Dental Schools of $\overparen{D}$ Guy's and St Thomas's Hospitals, $\vec{\omega}$ Guy's Hospital Campus, i London SE1 9RT. ì

\section{Sexuality and Medicine}

Earl E Shelp, editor, 271 pages, Dordrecht, Holland, £38.95, D Reidel, 1987

A new book in the D Reidel Publishing Company's Philosophy and Medicige $\overrightarrow{0}$ series demands scrutiny on mậy counts. Not the least of which must whether or not we need further음 information in the face of a plethora of publications that claim to be relevant to the scientific and philosophical study of sex in our culture today. This volume is $\stackrel{\odot}{\odot}$ the first of a series and is subtitled $\vec{F}$ Conceptual Roots. This seems an $\frac{\mathrm{O}}{3}$ unfortunate choice perhaps when one considers that concept is a re-fashioning of conceit a Middle English word of several derivations including 'a fanciful $\overline{3}$ ' notion' and 'a morbid seizure of the body or mind'. This book indeed $\frac{}{3}$ contains both fanciful notions and. morbid seizures. But it also contains aô lot of good sense and stimulating philosophy, not the least of which is음 contained in Alan Soble's admirable preface.

Understandably definitions figure largely in this book and fundamental is $\mathrm{N}$ a definition of what constitutes sexual $N$ health. Robert Kolochny seems to으 argue that sexual health is aw characteristic of those who do not appear in the sex therapist's consulting room, a view that does not seem to be $\frac{}{\mathbb{D}}$ shared by his co-authors Joseph Margolis and Sandra Harding. As might be expected in a book with the title Sexuality and Medicine some $\frac{\overrightarrow{\mathrm{D}}}{\mathrm{O}}$ authors, like Frederick Suppe, mount $\frac{}{\Phi}$ the platform to state the claim once again, that medical disciples are allo 